\title{
Zeynep Kamil Kadın Doğum ve Çocuk Hastanesindeki 50,645 Servikal Smear Sonucunun Değerlendirilmesi
}

\author{
Evaluation of 50,465 Cervikal Smear Results \\ in Zeynep Kamil Maternity and Pediatric Research and Training Hospital
}

\author{
Nermin Koç ${ }^{1}$ \\ 1. Zeynep Kamil Kadın Doğum ve Çocuk Hastanesi, Patoloji Kliniği, İstanbul, Türkiye
}

\section{$\ddot{O Z Z E T}$}

\begin{abstract}
Amaç: Servikal kanser dünyada kadınlar arasında en yaygın ikinci kanserdir ve gelişmekte olan ülkelerde, meme kanserinden sonra, kadinların malignitelerden ölümlerinin en sık nedeni olduğu düşünülmektedir. Erken dönemde tanısı için, Pap smear testi yaygın şekilde kullanılmaktadır. Bu çalışmada bölümümüzdeki servikal smear sonuçlarını değerlendirmeyi, bulgularımızı yine bölümümüzde, 2000-2005 yılları için yapılan benzer bir çalışmayla karşılaştırmayı ve literatür bilgileri eşliğinde tartışmayı amaçladık.
\end{abstract}

Gereç ve Yöntem: Ocak 2012 - Şubat 2016 arasındaki 50.465 Pap smear sonucunu geriye dönük olarak inceledik.

Bulgular: Ortalama hasta yaşı 44 (17-82) idi. Sitopatolojik inceleme sonuçlarında 7200 (\%14) inflamasyon, 988 (\%1.95) ASCUS, 187 (\%0.37) ASC-H, 370 (\%0.73) LSIL, $130(\% 0.25)$ HSIL, 41 (\%0.08) AGC, 3 skuamöz hücreli karsinom, 2 adenokarsinom saptand. Atipik skuamöz hücrelerin (ASCUS ve ASC-H), skuamöz intraepitelyal lezyona oranı $2.35 \mathrm{idi}$.

Sonuç: Çalışmamızda servikal sitolojik anormalliklerin oranı \%3.4 tür. Türkiye'den birçok farklı sonuç bildirilmiştir. Gerçek yaygınlığ saptamak için daha geniş vaka serileriyle daha çok çalışmaya ihtiyaç vardır.

Anahtar Kelimeler: servikal kanser; pap smear; tarama

\section{ABSTRACT}

Objective: Cervical cancer is the second most common type of cancer among women worldwide and considered to be the major cause of death from malignancy in women in developing countries after breast cancer. To detect cervical cancer at very early stages, Pap smear test is used widely.In this study we aimed to evaluate the cervical smear results of the women in our department and to compare with the results of a similar study that had been done for the years 2000-2005 and to discuss in the light of the literature.

Material and Method: We performed a retrospective research on 50.465 Pap smear results between January 2012 and February 2016.

Conclusion: The prevalence of cervical cytological abnormalities in our study was \%3.4. Many different results were published from Turkey. To determine the real prevalence, more studies with larger numbers are needed.

Keywords: cervical cancer; pap smear; screening

\section{İletişim Bilgileri:}

Sorumlu Yazar: Nermin KOÇ

Yazışma Adresi: Zeynep Kamil Kadın Doğum ve Çocuk Hastanesi, Patoloji Kliniği, Üsküdar, İstanbul

E-posta: nerminkoc@yahoo.com

Tel: +90 (532) 6400380

Makalenin Geliş Tarihi: 04.03.2016

Makalenin Kabul Tarihi: 25.04.2016

DOI: http://dx.doi.org/10.16948/zktb.36577 


\section{GİRIŞ}

Servikal kanser kadınlar arasında ikinci en yaygin kanser tipidir. Her y1l 500,000 yeni vaka ve 250,000 ölüm bildirilmektedir $(1,2)$. Gelişmekte olan ülkelerde daha yaygın olduğu halde, Türkiye' de yaygınlığı Avrupa ve dünyanın diğer ülkelerine göre daha düşük orandadır (3). Ülkemize ait epidemiyolojik veriler az olmakla birlikte 2003 deki Sağlık Bakanlığı verilerine göre, ülkemizde servikal kanser, tüm kadın kanserlerinde 10 . siradadır ve görülme oran 100,000 de 4.76 'dir (2). Servikal prekanseröz ve kanseröz lezyonların erken tanısında Pap smear testi, basit noninvaziv ve ucuz bir yöntemdir. Konvansiyonel yöntemin duyarlı11ğ1 \%30-70, özgüllüğü \%86-100 dür. Sivı bazlı sitolojinin duyarlılı̆̆ $1 \% 61-95$, özgüllüğü \%7882 ' dir (4). Etkin ve yaygın bir șekilde kullanımının, serviks kanseri riskini \%35-80 oranında azalttığ 1 düsünülmektedir (5). Tarama programları gelişmiş ülkelerde yaygın ve sistematik olarak kullanılırken, ülkemizde birkaç pilot bölge dışında tam olarak uygulanamamaktadır $(6,7)$. Gerçekçi tarama programlarının oluşturulabilmesi için ülkemizdeki gerçek yaygınlığını ve popülasyonlara göre dağılımını, artış veya azalıș eğilimini bilmek önemlidir.

Calıșmamızda hastanemiz jinekoloji polikliniklerine başvuran hastalardan alınan servikal smear sonuçlarını inceledik, premalign ve malign lezyonların oranlarını belirlemeye ve literatür eşliğinde tartışmaya çalıştık

\section{MATERYAL ve METOD}

Çalıșmaya Ocak 2012- Şubat 2016 arasında hastanemiz patoloji laboratuarında değerlendirilen 50,465 vaka alındı. Aynı hasta için yineleyen smearler, bilinen jinekolojik malignite öyküsü olanlar, histerektomize hastalar çalışma dışı bırakıldı. Smearler sıvı bazlı (thinprep) prosedürüne göre otomatik olarak hazırlanıp, Papanicolaou ile boyandi. Patoloji uzmanlar1 tarafindan 2001 y1l Bethesda derecelendirme sistemine göre; önemi belirsiz atipik skuamöz hücreler (ASCUS), yüksek dereceli lezyonun dişlanamadığı atipik skuamöz hücreler(ASC-H), düşük dereceli skuamöz intraepitelial lezyon (LSIL), yüksek dereceli skuamöz intraepitelial lezyon (HSIL), atipik glandüler hücreler (AGC), skuamöz hücreli karsinom (SCC), adenokarsinom olarak değerlendirildi.

\section{BULGULAR}

Ortalama hasta yaşı 44 idi (17-82). 515 (\%1.1) smear yetersiz idi. 7,200 (\%14) vakada inflamasyon mevcuttu. 1,721 vakada (\%3.4) epitelyal hücre anormallikleri tespit edildi. Bunlardan 988'i (\%1.95) ASCUS, 187'si (\%0.37) ASC-H, 370’i (\%0.73) LSIL, 130’u $(\% 0.25)$ HSIL, 41’i $(\% 0.08)$ AGC, 3'ü skuamöz hücreli karsinom, 2'si adenokarsinom idi (Tablo 1). Atipik skuamöz hücrelerin, skuamöz intraepitelial lezyona oranı (ASC/SIL) 2.35 idi.

Tablo 1: Servikal Sitoloji Sonuçları
\begin{tabular}{|c|c|c|}
\hline Servikal Sitoloji & Vaka Sayısı & Oran(\%) \\
\hline Normal & 41029 & 81 \\
\hline Inflamasyon & 7200 & 14 \\
\hline Yetersiz & 515 & 1.1 \\
\hline ASCUS & 988 & 1.95 \\
\hline ASC-H & 187 & 0.37 \\
\hline LSIL & 370 & 0.73 \\
\hline HSIL & 130 & 0.25 \\
\hline AGC & 41 & 0.08 \\
\hline SCC & 3 & \\
\hline Adenokarsinom & 2 & \\
\hline
\end{tabular}

\section{TARTIŞMA}

Serviks kanseri halen kadınlarda 2. en s1k görülen kanserdir ve 2002 de dünya çapında 239,000 kadının ölümüne neden olmuştur (6). Servikal lezyonların premalign aşamada tespit ve tedavi edilmesi hastalığa yakalanma ve hastalıktan ölüm oranlarını düşürür. Pap smear ile tarama yöntemi 1942 'de Papanicolaou tarafindan tanımlanmış, maliyet açısından etkin, noninvaziv, basit ve etkili bir yöntemdir $(8,9)$. Tayvan'dan yapılan bir çalıșmada 1995-2006 y1lları arasında Papsmear ile servikal kanser tarama programı uygulanarak kanser oranı \%47.8 azaltılmıştır (9). Gelişmiş ülkelerde serviks kanserinin daha az görülmesinin nedeni Pap smear metodunun 50 yıldır etkin bir șekilde kullanılmasıyla açıklanmıștır $(1,5,6)$. Pap smear yapılma oranları Pakistanda \%2.6, Güney Afrikada \%27, Amerika Birleşik Devletlerinde \%93'tür (5). Türkiye'de ise değișik bölgelerden farklı sonuçlar bildirilmiștir. Erbil ve arkadaşlarına göre \%11.8, Gürel ve arkadaşlarına göre $\% 30.4$, Karaca ve arkadaşlarına göre $\% 16.2$, Akyüz ve arkadaşlarına göre ise $\% 51.2$ $\operatorname{dir}(5,10,11,12)$. Ülkemizin genelini yansitan epidemiyolojik çalışmalar maalesef az sayıdadir.

Pap smear yönteminin etkinliğini saptamak için kullanılan bazı kalite kontrol yöntemleri mevcuttur. Anormal smear oranı (anormal epitelyal hücre oranı) ve ASC/SIL oranı en 
yaygın sıklıkla kullanılanlardır (13). Anormal smear, ASCUS, ASC-H, LSIL, HSIL, AGC ve karsinomların toplamıdır. Yüksek gelir düzeyine sahip ülkelerde bu oran \%1.5-7.3 arasında değișmekte iken, ülkemizde \%1.2-12.6 dir (13). Türkmen ve arkadaşlarının çalışmasında ise \%4.3'tür (13). Türk Servikal Kanser ve Servikal Sitoloji Araştırma grubunun (TSK ve SSA grup ) yaptığ 1 Türkiye genelini yansıtan, toplam 140,334 hastanın değerlendirildiği bir çalışmada ise bu oran \%1.8'dir (14). Çalışmamızda bu oran \% 3.4 ile bu değerin üstündedir. Bu sonuç belki de popülasyonumuzun servikal lezyonlar için risk grubunda olan düşük-orta sosyoekonomik düzeyiyle ilgili olabilir. ASC/SIL oranı ise ASCUS ve ASC-H' in toplaminin LSIL ve HSIL in toplamına oranıdır. Onerilen oran bazı çalışmalarda 2-3 arası bazılarında ise 0.87 ve 4.49 arasıdır $(13,15)$. Ülkemizde ise değișik çalişmalarda 3.28 ve 12.6 arası rakamlar bildirilmiştir. Türkmen ve arkadaşlarının çalışmasında \%2.12'dir (13). Yine aynı grubun (TSK ve SSA grup) çalışmasında bu oran 2.83 'tür (14). Çalışmamızdaki oran 2.35 olup bu değere yakındır.

Ülkemizdeki anormal servikal sitoloji sıklığı Avrupa ve Kuzey Amerika'ya göre daha düşüktür $(14,2)$. Amerika Birleşik Devletleri’nde yapılan bir çalışmada ASCUS, LSIL, HSIL, AGC oranları sirasiyla $\% 3.9, \% 2.1, \% 0.5, \% 0.2$ olarak bildirilmiștir (2). Ülkemizde ise farklı çalışmalarda farklı sonuçlar mevcuttur. Karabulut ve arkadaşlarının çalışmasında ASCUS, ASC-H, LSIL, HSIL oranlar1 sirasiyla $\% 0.54$, $\% 0.15, \% 0.07$ dir (16). İnal ve arkadaşlarının 32,026 vakalık çalıșmasında sirasıyla \%1.9, $\% 0.1, \% 0.5, \% 0.1, \% 0.2$ 'dir (17). Eroğlu ve arkadaşlarının çalışmasında $\% 0.5, \% 0, \% 0.02$, $\% 0.02$ (18), Öner ve arkadașlarının çalıșmasında ise \%1.08, \%0, \%0.036, \%0.036 dir (19). Çelik ve arkadaşlarının çalışması ise en yüksek değerlere sahiptir; toplam atipik skuamöz hücrelerin (ASC) oranı \%4.8, LSIL \% 1.8, HSIL $\% 1.1$, AGUS \%0.9 dur (20). Türkiye genelini yansıtan aynı grubun (TSK ve SSA grup) çalişmasinda bu oranlar sirasiyla \%1.07, \%0.07, $\% 0.3, \% 0.17$ ve $\% 0.08$ dir (14). Bizim çalıșmamız sirasiyla \%1.95, \%0.37, \%0.73, \%0.25 ve \%0.08 ile İnal ve arkadaşlarının sonuçlarına yakındır. Şüphesiz ki bu sonuçlar çalışmalara dahil edilen farklı popülasyonlar, farklı risk grupları ve vaka sayısındaki farklılıktan kaynaklanmaktadır.

2000-2005 y1llarını kapsayan, yine hastanemizde ve yine aynı uzunlukta bir zaman diliminde yapılan, bir çalışmada ise toplam 28,649 pap smear değerlendirilmiştir (21). Anormal epitelyal hücre oran1, \%2.93'tür ve ASCUS, ASC-H, LSIL, HSIL, AGC oranları sirasıyla
$\% 2.45, \% 0, \% 0.23, \% 0.15, \% 0.1$ 'dir. Bizim çalışmamızda, bu çalışmaya göre hem vaka sayısı artmış, hem de anormal epitelyal hücre oranları artmıştır (sırasıyla 50,465 ve \%3.4). Anormal epitelyal hücre oranındaki artış gerçek bir artış olabileceği gibi, bu dönemdeki smearlerin konvansiyonel yöntemlerle değerlendirilmesinden, çalışmamızda ise sıvı bazlı sitolojinin kullanılmasından da kaynaklanıyor olabilir. Bilindiği üzere sıv1 bazlı sitolojinin, epitelyal anormallikleri saptama oranının daha fazla olduğuna dair görüşler mevcuttur (21).

Sonuçta servikal sitoloji anormalliklerinin sıklığı değişiklik göstermektedir. Etkin ve yaygın tarama programları, aynı popülasyonda farklı zamanlı çalışmaların yapılması ve karşılaştırılması ile ülkemizdeki gerçek oranları ve yıllar içindeki artma veya azalma eğilimini tespit etmek mümkün olacaktır.

\section{KA Y N A KL AR}

1. Isaoglu U, Yilmaz M, Delibas IB., Bilici AE, Kabalar M E. Evaluation of 37, 438 consecutive cervical smear results in the Turkish population. Arch Med Scl 2015; 11(2): 402-5.

2. Atilgan R, Celik A, Boztosun A, Ilter E, Yalta T, Ozercan R. Evaluation of cervical cytological abnormalities in Turkish population. Indian J Pathol Micr 2012; 55(1): 52-5.

3. Yılmaz HH, Yazıhan N, Tunca D, Sevinç A, Olcayto EÖ, Özgül $N$, et al. Cancer trends and incidence and mortality patterns in Turkey. Jpn J Clin Oncol 2011;41(1):10-6

4. Kulasingam SL, Hughes JP, Kiviat N B, Mao C, Weiss NS, Kuypers JM, Koutsky LA. Evaluation of human papillomavirus testing in primary screening for cervical abnormalities: comparison of sensitivity, specificity, and frequency of referral. Jama 2002; 288(14): 1749-57.

5. Erbil, N, Tezcan Y, Gür EN, Yıldırım M, Alış N. Factors affecting cervical screening among Turkish women. Asian Pac J Cancer Prev 2010; 11(6): 1641-4.

6. Demirhindi H, Nazlican E, Akbaba M. Cervical Cancer Screening in Turkey: A Community-Based Experience after 60 Years of Pap Smear Usage. Asian Pac J Cancer Prev 2012; 13(12): 6497-500.

7. Uysal A, Birsel A. Knowledge about cervical cancer risk factors and pap testing behaviour among Turkish women. Asian Pac J Cancer Prev 2009;10(3): 345-50.

8. Yang BH, Bray F I, Parkin DM, Sellors J W, Zhang ZF. Cervical cancer as a priority for prevention in different world regions: an evaluation using years of life lost. Int J Cancer 2004; 109(3): 418-24.

9. Chen YY, You SL, Chen CA, Shih LY, Koong SL, Chao KY, et al . Effectiveness of national cervical cancer screening programme in Taiwan: 12-year experiences. Brit J Cancer 2009; 101(1): 174-7

10. Gürel SA, Gürel H, Topçuoğlu A. Investigation of rate and determinants of Pap-test in women attending for a gynecological examination. Turkiye Klinikleri J Gynecol Obst 2009; 19(2): 62-6. 
11. Karaca M. How common is pap smear test known and performed. Turkiye Klinikleri J Gynecol Obst 2008; 18(1): 22-8

12. Akyüz A, Güvenç G, Yavan T, Çetintürk A, Kök G. Evaluation of the Pap smear test status of women and of the factors affecting this status. Gulhane Med J. 2006; 48(1):25-9.

13. Türkmen IÇ, Başsüllü N, Korkmaz P, Günenç B, Baykal C M, Güdücü N, et al. Patients with Epithelial Cell Abnormality in PAP Smears: Correlation of Results with Follow-Up Smears and Cervical Biopsies/PAP Smearde Epitel Hücre Atipisi Saptanan Hastalar: Sonuçların Takip Smear ve Servikal Biyopsi ile Uyumlart. Turk Patoloji Derg 2013;29(3): 179-84.

14. Cancer, Turkish Cervical, and Cervical Cytology Research Group. Prevalence of cervical cytological abnormalities in Turkey. Int J Gynecol Obstet 2009;106(3): 206-9.

15. Nascimento AF, Cibas ES. The ASC/SIL ratio for cytopathologists as a quality control measure. Am J Clin Pathol 2007; 128(4): 653-6.

16. Karabulut A, Alan T, Ekiz MA, Iritaş A, Kesen Z, Yahşi S. Evaluation of cervical screening results in a population at normal risk. Int J Gynecol Obstet 2010 ;110(1): 40-2.

17. Inal MM, Köse Ş, Yildirim Y, Özdemir Y, Töz E, Ertopçu K, et al. The relationship between human papillomavirus infection and cervical intraepithelial neoplasia in Turkish women. Int $J$ Gynecol Cancer 2007; 17(6): 1266-70.

18. Eroğlu C, Unlu Y, Eryilmaz MA, Gonenc O. Cervicovaginal smear screening experience early cancer diagnosis-screening and Education Center Konya Education and Research Hospital. Jinekoloji Obstetrik ve Neonatoloji Tip Dergisi 2008; 21: 91-6.

19. Oner S, Demirhindi H, Erdogan S, Tuncer I, Akbaba M. Gynecologic examination findings and pap smear screening results of women in Dogankent, Turkey. Turk J Public Health 2004; 2(2); 85-91.

20. Celik C, Gezginc K, Toy H, Findik S, Yilmaz O. A comparison of liquid-based cytology with conventional cytology. . Int $J$ Gynecol Obstet 2008; 100(2): 163-6.

21. Yalti S, Gürbüz B, Bilgic R, Cakar Y, Eren S. Evaluation of cytologic screening results of the cervix. Int J Gynecol Cancer 2005; 15(2): 292-4.

22. Akamatsu S, Kodama S, Himeji Y, Ikuta N, Shimagaki N. A comparison of liquid-based cytology with conventional cytology in cervical cancer screening. Acta Cytol 2012; 56(4): 370-4. 